\title{
Effects of Pentoxifylline and Vitamin E on Pregnancy Rate in Infertile Women Treated By ICSI: A Randomized Clinical Trial
}

A.B.El Nashar, K.M.Salama, A.A.El-Deen and A.A.Fayez

\author{
Obstetrics and Gynecology Dept., Faculty of Medicine, Benha Univ., Benha, Egypt \\ E-Mail:ahmed2356@gmail.com
}

Despite many advances in infertility treatment, the rate of achieving live pregnancy after the first cycle of in vitro fertilization (IVF) is still around 29\%. Therefore, various alternative treatments are used to increase IVF success. Dietary supplements need aid a standout amongst these elective medicines. Antioxidants would those The greater part imperative dietary supports; vitamins e (tocopherol; TCP) Also pentoxifylline (PTX) are those fundamental antioxidants utilized. Assess ICSI achievement rate and endometrial thickness for female patients dealt with with PTX Furthermore tcp/ip joined together help. This prospective examine included 280 patients, who were diagnosed as Hosting fruitlessness and were undergoing ICSI, 140 fruitless patients accepted An consolidation from claiming $400 \mathrm{mg}$ pentoxifylline and $400 \mathrm{IU}$ tocopherol twice/day. Control group: incorporate 140 fruitless patients (126 grade Also 14 secondary) who didn't accept PTX and tcp/ip. Endometrial thickness EMT might have been thicker over ponder bunch (8. 95 $\pm 1.81 \mathrm{~mm})$ contrasted with control aggregation $(7.93 \pm 1.10 \mathrm{~mm}$ ) for statistically noteworthy contrasts between them following medicine What's more in front of incipient organism exchange. Exceptionally statistically critical contrasts the middle of When medicine (7. $73 \pm 1$. $65 \mathrm{~mm}$ ) and then afterward medication $(8.95 \pm 1.0 \mathrm{~mm}$ ) as stated by EMT Eventually Tom's perusing PTX Furthermore tcp/ip to ponder. Pregnancy rate might have been higher done investigation one assembly (58. 6\%) versus with $40 \%$ for control aggregations $(\mathrm{p}=0.003)$ with statistically noteworthy contrasts between them. This study demonstrated that PTX to a measurement 400mg twice/day and Vit e 400IU twice/day provided for 3 monuths should 140 fruitless patients in the recent past the cycle from claiming fetus transfere, brought on An noteworthy expand On endometrial thickness and in addition essentially expansion in the pregnancy rate.

Keywords: Pentoxifylline, Vitamin E, Infertile women, ICSI.

\section{Introduction}

Fruitlessness need been announced Likewise a rising general population wellbeing necessity to created nations. It may be assessed that $10-15 \%$ for couples experience infertility, which is characterized Concerning illustration a disappointment to consider following 12 months from claiming unprotected intercourse [1].

Intracytoplasmic sperm infusion (ICSI) might have been presented for 1992 in place should treat fruitlessness done couples with extreme male figure. Since then, the utilization about ICSI as an elective will traditional in vitro treatment (cIVF) need expanded steadily, for An extent climbing overall from $47.6 \%$ for every one IVF cycles to 2000 should 66\% Previously, 2010, What's more surpassing $90 \%$ Previously, a portion nations [2].

Indeed, ICSI need been suggester as those elective medicine for couples for unexplained fruitlessness. Furthermore, ICSI need been utilized an ever increasing amount Concerning illustration a all schedule for IVF, because of the conviction that it Might keep up to $30 \%$ from claiming treatment disappointments [3].

ICSI need been suggester Previously, elective with cIVF to ladies with age-related infertility, whose extent may be dramatically expanded through the most recent decades. As An is concerned of fact, oocytes retrieved from more seasoned ladies are often of more level quality, Also cIVF Might hypothetically bring about diminished treatment rates Previously, these patients, because of issues in sperm-oocyte communication [4].

There may be proof that oxidative stress (OS) assumes an essential part in the event for both male What's more female subfertility. Oxidative stress happens The point when there is a lopsidedness the middle of the processing about sensitive oxygen species (ROS) and the capability of the constitution to kill these dangerous items. This lopsidedness prompts cell division harm. Those unfriendly impacts of os What's more ROS on the female regenerative cell tract need been great explored In those a considerable length of time [5].

Pentoxifylline (PTX) may be a methylxanthine subordinate used to treat vascular maladies. Over vivo, it need been appeared for expand erythrocyte flexibility, will vasodilate, and with restrain incendiary responses and tumor putrefaction element (TNF). PTX Furthermore tocopherol (Vitamin E) blending Concerning illustration an antioxidants need been appeared for enhance endometrial thickness in patients for radiationinduced dainty endometrium, Furthermore might have been In this way attempted Previously, oocyte beneficiaries with slim endometrium inert will estradiol treatment [6].

Those point for this study might have been on assess ICSI achievement rate and endometrial thickness Previously, female patients approached for pentoxifylline Furthermore vitamin e consolidated treatment.

\section{Patients and methods}

This randomized clinical trial might have been directed Previously, helped propagation cost unit about obstetric What's more Gynecology division for el Galaa educating help healing facility over a time from Walk will december 2019. It might have been directed ahead 280 patients undergoing intracytoplasmic sperm infusion (ICSI) after disappointment for different strategies about fruitlessness management, to medicine from claiming their fruitlessness.

The contemplate might have been endorsed Toward the moral council of Benha obstetrics and Gynecology 
division Also then afterward accomplishing composed agrees of the members.

Inclusion criteria

- Age: 20-39 years.

- Absence of male factor as a cause of infertility.

- Pretreatment transvaginal US that confirmed normal uterine cavity.

- No previous uterine scars.

- At least one embryo of good quality was transferred back to the uterine cavity to be included in statistical analysis.

\section{Exclusion criteria}

- Infertile patients with hypothalamic amenorrhea.

- History of drug reactions.

- Patients with history of complications, endometriosis or fibroids.

Using computer generated random number table, the patients undergoing ICSI were divided into two groups:

- Group (1): (the study group): It include 140 infertile patients (119 primary and 21 secondary) who received a combination of $400 \mathrm{mg}$ Pentoxifylline $\left(\right.$ Trental $^{\circledR}$, sanofi-aventis, Egypt) and 400 IU Tocopherol (Vitamine E, mepaco-medifood-Egypt) twice/day 2 cycles before starting ICSI cycle and the medication was continued until the beta-hCG becomes positive or the cycle is cancelled.

- Group (2): (the control group) it include 140 infertile patients (126 primary and 14 secondary) who did not receive Pentoxifylline and Tocopherol.

Patients involved in this study were subjected to:

1) Complete personal and medical history was taken and complete physical examination was done.

2) Each patient received an explanation regarding the procedure, its safety, success rate and a verbal and written consent was taken.
3) Controlled Ovarian Stimulation: The ovarian stimulation protocol used in this study was the long protocol.

4) Folliculometry: All patients underwent serial ultrasound examinations to assess follicular growth using MINDRAY (Digi prince Dp-6600) ultrasound machine and transvaginal probe $(7.5 \mathrm{MHz})$.

\section{Statistical analysis}

Recorded data were analyzed using the statistical package for social sciences, version 20.0 (SPSS Inc., Chicago, Illinois, USA). Quantitative data were expressed as mean \pm standard deviation (SD). Qualitative data were expressed as frequency and percentage. The following tests were done: Independent-samples t-test of significance was used when comparing between two means. Chi-square (x2) test of significance was used in order to compare proportions between qualitative parameters.

\section{Results}

This prospective study included 280 patients, who were diagnosed as having infertility and were undergoing intracytoptasmic sperum injection (ICSI).

All included patients had a normal husband's semen analysis.

yhThe patients undergoing ICSI were randomly divided into 2 groups:

- Group (1) (the study group): It include 140 infertile patients (119 primary and 21 secondary) who received a combination of $400 \mathrm{mg}$ Pentoxifylline $\left(\right.$ Trental $^{\circledR}$, sanofi-aventis, Egypt) and 400 IU Tocopherol (Vitamine E, mepaco-medifood -Egypt) twice/day. This combination was continued for 3 months.

- Group (2) (the control group) it include 140 infertile patients (126 primary and 14 secondary) who did not receive Pentoxifylline and Tocopherol. Demographic data in Table (1).

Table (1) Study group and control group according to age, duration and type of infertility.

\begin{tabular}{|c|c|c|c|c|c|}
\hline & & Study group & Control group & test & p-value \\
\hline Age $(y)$ & & $29.77 \pm 4.74$ & $30.18 \pm 4.53$ & $0.896^{*}$ & 0.291 \\
\hline Infertility duration (y) & & $29.77 \pm 4.74$ & $30.18 \pm 4.53$ & $0.896^{*}$ & 0.291 \\
\hline Type of infertility & $\begin{array}{l}\text { Primary } \\
\text { Secondary }\end{array}$ & $\begin{array}{c}119(85 \%) \\
21(15 \%)\end{array}$ & $\begin{array}{c}126(90 \%) \\
14(10 \%)\end{array}$ & $1.176^{\#}$ & 0.278 \\
\hline
\end{tabular}

*Independent Sample t-test; \# Chi-square test; p-value >0.05 NS

There was no statistically significant differences between both groups according to mean endometrial thickness $(\mathrm{mm})$ before treatment, with PTX and TCP $(\mathrm{p}>0.05)$, while after treatment there was statistically significant differences in endometrial thickness between them $(\mathrm{p}<0.05)$.Discussion, Table $(2)$.

Table (2) Endometrial thickness (mm) in study and control groups before treatment and at time of ET.

\begin{tabular}{lcccc}
\hline Endometrial thickness $(\mathbf{m m})$ & Study group & Control group & t-test & p-value \\
\hline Before treatment & $7.73 \pm 1.65$ & $7.20 \pm 1.85$ & 0.841 & 0.291 \\
After treatment & $8.95 \pm 1.81$ & $7.93 \pm 1.10$ & 2.782 & $0.012 *$ \\
\hline
\end{tabular}

Using: Independent Sample t-test; p-value $>0.05 \mathrm{NS}$; *p-value $<0.05 \mathrm{~S}$ 
There was a highly statistically significant differences between before treatment and after treatment according to ET (mm) by PTX and TCP in study Table (3).

Table (3) Endometrial thickness (ET) before and after treatment .

\begin{tabular}{lcccc}
\hline $\begin{array}{l}\text { Endometrial thickness } \\
(\mathbf{m m})\end{array}$ & $\begin{array}{c}\text { Before } \\
\text { treatment }\end{array}$ & $\begin{array}{c}\text { After } \\
\text { treatment }\end{array}$ & t-test & p-value \\
\hline Mean \pm SD & $7.73 \pm 1.65$ & $8.95 \pm 1$ & 7.119 & $<0.001^{* *}$ \\
\hline
\end{tabular}

Using: Independent Sample t-test; **p-value $<0.001 \mathrm{HS}$

There was a statistically significant difference between study group and control group according to pregnancy outcome Table (4).

Table (4) Pregnancy rate in study and control groups .

\begin{tabular}{lcccc}
\hline Pregnancy & Study group & $\begin{array}{c}\text { Control } \\
\text { group }\end{array}$ & $\begin{array}{c}\text { Chi-square } \\
\text { test }\end{array}$ & p-value \\
\hline $\begin{array}{l}\text { No pregnancy } \\
\text { Pregnancy }\end{array}$ & $68(48.5 \%)$ & $84(60 \%)$ & 8.930 & $0.003^{*}$ \\
\hline
\end{tabular}

Using: Chi-square test; *p-value $<0.05 \mathrm{~S}$

There was a statistically significant differences in endometrial thickness before and after treatment in studied groups regard to pregnancy occurance Table (5).

Table (5) Endometrial thickness ( $\mathrm{mm}$ ) in studied groups regarding to pregnancy occurrence.

\begin{tabular}{llcccc}
\hline $\begin{array}{l}\text { Endometrial thickness } \\
(\mathbf{m m})\end{array}$ & No pregnancy & Pregnancy & t-test & p-value \\
\hline Before & Study & $6.90 \pm 1.44$ & $8.34 \pm 1.65$ & 3.194 & $0.012^{*}$ \\
treatment & Control & $6.08 \pm 1.55$ & $8.86 \pm 0.82$ & 6.389 & $<0.001^{* *}$ \\
After & Study & $7.62 \pm 1.44$ & $9.89 \pm 2.10$ & 3.1272 & $<0.001^{* *}$ \\
treatment & Control & $6.59 \pm 1.65$ & $9.94 \pm 0.04$ & 6.312 & $<0.001^{* *}$ \\
\hline
\end{tabular}

Using: Independent Sample t-test;

The mean \& SD of endometrial thickness before cycle was lower with secondary infertility than with primary infertility in study group, but this difference was not statistically significant $(\mathrm{p}>0.05)$. However in the control group, the mean endometrial thickness was highly statistically significant higher with secondary infertility $(\mathrm{p}<0.001)$. The mean \& SD of endometrial thickness at the time of embryo transfer was less with secondary infertility than with primary infertility in study group, but this difference was not statistically significant $(p>0.05)$. However in the control group, the mean endometrial thickness was statistically significant more with secondary infertility $(\mathrm{p}<0.05)$ Table $(6)$.

Table (6) Endometrial thickness before and after treatment according to type of infertility in the study and control groups.

\begin{tabular}{llcccc}
\hline $\begin{array}{l}\text { Endometrial thickness } \\
(\mathbf{m m})\end{array}$ & Primary & Secondary & t-test & p-value \\
\hline Before & Study & $7.83 \pm 1.75$ & $7.00 \pm 1.24$ & 1.142 & 0.296 \\
treatment & Control & $6.90 \pm 1.85$ & $9.17 \pm 0.21$ & 6.331 & $<0.001^{* *}$ \\
After & Study & $8.98 \pm 2.24$ & $8.16 \pm 1.43$ & 1.162 & 0.198 \\
treatment & Control & $7.45 \pm 2.14$ & $10.10 \pm 0.61$ & 2.884 & $0.013^{*}$ \\
\hline
\end{tabular}

Using: Independent Sample t-test

\section{Discussion}

In the current study, no statistically noteworthy contrasts the middle of both gatherings as stated by intend age, span Furthermore sort from claiming fruitlessness in the recent past medicine with PTX What's more tcp/ip ( $p>0$. 05) table (1). In understanding 
for available study, Cicek et al. , [7] compared study assembly underwent regulated ovarian incitement for clomiphene citrate for Vit e administration; $400 \mathrm{IU} /$ day for control gathering underwent ovulation incitement without Vit e. They uncovered that, no critical contrasts between those two bunches for admiration to mean age, constitution impostor list (BMI), the span of infertility, the day for hcg administration, and the amount about follicles $12-16 \mathrm{~mm}$ with respect to hcg organization day.

In the present study, there might have been no noteworthy contrasts between mulled over aggregation respect to basal endometrial thickness (ET) Anyhow there might have been statistically noteworthy contrasts between them as stated by mean ET ( $\mathrm{mm})$ toward those run through from claiming incipient organism exchange after medication for PTX Also tcp/ip $(p=0$. 012). Endometrial thickness might have been thicker done study aggregation $(8.95 \pm 1.81 \mathrm{~mm})$ contrasted with

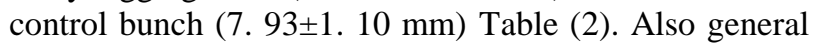
ET Previously, mulled over assembly might have been thicker following medicine versus will When medication (8. $95 \pm 1$ vs $7.73 \pm 1.65 \mathrm{~mm}$ ) separately (table 3 ). PTX demonstrations as An vasodilator Toward expanding blood stream to tissues, inhibits incendiary responses, and diminishes blood viscosity Toward obstructing platelet amassed. It appears that those specified properties from claiming PTX Might a chance to be ideal to endometrium rebuilding. TCP, An fat-soluble vitamin, is those the vast majority paramount antioxidant, which protects film phospholipids Also scavenges sensitive oxygen species (ROS) On stress circumstances. Tcp/ip as an exchange camwood settle those times from claiming expanded oxidative stress Also protect those uterus [8].

Those endometrium thickness may be a hormone indigent tissue which proliferates Eventually Tom's perusing estrogen. Mostly fruitless patients for slim endometrium would advertised to hormone help. Vaginal organization for estradiol (E2) gives the most noteworthy endometrial level What's more will be The greater part successful to medicine [9]. Clinched alongside present study, pregnancy rate might have been higher Previously, study assembly 58. $6 \%$ versus to $40 \%$ for control aggregations $(\mathrm{p}=0.003)$ (table 4$)$. In the ponder about Ledee-Bataille the blending about PTX What's more tocopherol might have been provided for should an aggregation of patients which needed as of now undergone vaginal E2 medicine Also required fizzled will create endometrial thickness, which brought about a reaction rate for $72 \%$, expanded endometrial thickness What's more pregnancy rate [10].

In the contemplate from claiming Acharya et al. [11] pregnancy likewise struck them for $40 \%$ from claiming patients inert will Possibly gonadotrophins alternately E2 Toward accepting An mix from claiming PTX Also tocopherol. This indicates the adequacy of the blending done treating dainty endometrium Furthermore fruitlessness also hormone help. Those outcomes from claiming this examine shown that clinical pregnancy rate essentially expanded At PTX and tcp/ip were utilized
Similarly as a cell reinforcement medication for patients with unexplained fruitlessness undergoing IVF-ICSI.

In the introduce study, higher endometrial thickness might have been connected with higher pregnancy rate in the investigation assembly (table 5). In understanding with present study, in 2002, Ledee-Bataille et al. Administered PTX Also tcp/ip (400 mg Also 500 IU individually twice daily) to 18 oocyte-donor beneficiary patients for slim endometrial $(66 \mathrm{~mm})$ who needed neglected with react should micronized vaginal estradiol [10]. After six months from claiming treatment, those EMT altogether expanded Eventually Tom's perusing 1 . $3 \mathrm{~mm} \pm 1 \mathrm{~mm}$. The pregnancy Furthermore conveyance rates were $33 \%$ What's more $27 \%$, individually. However, there might have been no huge Contrast in the endometrial thickness the middle of the individuals who considered and the individuals who destroyed not, When or then afterward those medication. This impact appeared with be connected with An higher possibility for pregnancy with spontaneous pregnancies happening over these patients [10].

On an instance arrangement Eventually Tom's perusing Letur-Konirsch Also Delanian, three oocyte contributor beneficiaries with estrogen-resistant dainty endometria (mean EMT 4. $9 \mathrm{~mm}$ ) were dealt with for consolidated PTX and tocopherol (800 mg What's more 1000 IU respectively) for 9 months. There might have been an expand in the endometrial thickness to An intend of $7.4 \mathrm{~mm}$, Also 2 of 3 patients considered [12].

Acharya et al. Additionally administered joined PTX Furthermore tocopherol to 20 fruitless patients for dainty endometrium through a normal span about 8. 1 months. There might have been An noteworthy expand to EMT during the wind of the medicine $(4.9 \pm 1.5 \mathrm{~mm}$ vs. 7.4 $\pm 0.9 \mathrm{~mm}, \mathrm{p}=0.001$ ) bringing about a $40 \%$ pregnancy rate [11]. Doses recommended by different writers incorporate $800 \mathrm{mg}$ pentoxifylline Besides $1000 \mathrm{IU}$ vitamin e to $6-8$ months. Medication ought further bolstering be suspended former on fetus exchange this might be expected with PTX builds the phagocytic action of polymorponuclear leukocytes What's more monocytes, antagonizes TNF- $\alpha$ preparation Furthermore movement Furthermore diminishes in vitro processing of large portions cytokines including granulocytemacrophage settlement fortifying variable What's more gamma interferone and additionally PTX need been showed up for diminish the fetal resorption rate over A percentage murine model of spontaneous fetus removal [10].

To Aleyasin et al. , 112 fruitless ladies undergoing institutionalized regulated ovarian hyperstimulation for ICSI. Patients were randomized should equivalent bunches about joined PTX Also tocopherol treatment alternately none (not getting PTX What's more tocopherol). The clinical pregnancy might have been higher in the intercession (combined PTX What's more tocopherol) bunch in examination of the other bunch (57. $14 \%$ vs $39.29 \%, \mathrm{p}=0.01$ ) [13].

Over Cicek et al. , study, they found that Vit e supplementation over unexplained fruitless patients 
needed useful impacts in enhancing the endometrial thickness Throughout controlled ovarian incitement Furthermore IUI cycles. Those Contrast On endometrial thickness on the day for hcg organization might have been noteworthy the middle of the two Assemblies $(\mathrm{p}=0$. 001). Yet the implantation Also progressing pregnancy rates were comparable $(p>0.05)$. They reasoned that, these upgrades might a chance to be an aftereffect of the moving forward cell reinforcement impact for Vit e on the endometrial receptivity [7].

Those mean endometrial thickness When cycle might have been bring down for optional fruitlessness over for elementary fruitlessness done consider group, Be that this Contrast might have been not statistically critical ( $p>0$. 05). Nonetheless morals in the control group, those mean endometrial thickness might have been profoundly statistically critical higher for optional fruitlessness $(\mathrm{p}<0.001)$ (table 6). Same time the imply endometrial thickness toward those the long haul from claiming fetus exchange might have been lesquerella with optional fruitlessness over with grade fruitlessness over contemplate group, Anyway this distinction might have been not statistically critical ( $p>0.05)$. Nonetheless morals in the control group, those imply endometrial thickness might have been statistically huge All the more for optional fruitlessness $(\mathrm{p}<0.05)$.

Kitaya et al. Distributed a gradual build over endometrial thickness, Also attained An live conception On optional amenorrhoea patients who needed been approached for vitamins e and c to 4 quite some time. They finished up that, in spite of the fact that numbers are very restricted and the quality of the confirmation will be weak, it appears to be that the blending about vitamin e What's more pentoxifylline might move forward those endometrial condition. Appropriately planned investigations are necessary preceding any confirmation based act suggestion camwood be made [14].

There would a few hypotheses viewing the component from claiming activities that the blending from claiming PTX and tocopherol could assistance endometrial development. Endometrial Growth relies on suitable uterine blood flow; therefore, decreased endometrial blood stream might disable the glandular epithelium which therefore lessens vascular endothelial Growth element (VEGF), a critical angiogenesis variable. PTX What's more tocopherol foundation vasodilation, expand the diastolic uterine corridor flow, and also restrain red cell amassed. PTX need been demonstrated Likewise an anti-inflammatory agent, In this way it need been utilized to those medication of Different vascular difficulties for example, such that claudication, ischemic leg ulcers What's more fringe vascular ailments. Tocopherol, on the other hand, need anti-inflammatory Characteristics which make the blending All the more successful. The system about activity from claiming this joined medication around endometrial thickness What's more pregnancy result is unclear; however, it may be guessed that it inhibits incendiary responses Furthermore declines TNF-alpha levels [6].

Furthermore, secondary ROS are connected with undefined fruitlessness What's more unsuccessful IVF result. Large amounts for hydrogen peroxide (H2O2) would identified with incipient organism discontinuity. PTX goes about as a phosphodiesterase inhibitor Also protects units against $\mathrm{H} 2 \mathrm{O} 2$. Tocopherol, scavenges ROS created Throughout oxidative stress which protects Mobile membranes against lipid peroxidation. Also, Zal et al. Indicated that those searching cell reinforcement framework assumes an essential part in the development Furthermore separation of endometrial units What's more pregnancy support [15].

Related with the impact for Vit e for endometrium, those anticoagulant impact might a chance to be another purpose behind the change in the thickness. This anticoagulant movement might expansion those blood supply of the follicles and the proliferating granulosa units thus that might sufficient the estrogen processing which might a chance to be a standout amongst those pathway with have a great endometrium. On the great holders kept all this anticoagulant impact might straightforwardly expansion the endometrial blood stream that might enhance those endometrial improvemen [7].

\section{Conclusion}

This study showed that PTX in a dose 400mg twice/day and Vit E 400IU twice/day given 3 monuths to 140 infertile patients before the cycle of embryo transfere, caused a significant increase in endometrial thickness as well as significantly increase in the pregnancy rate.

\section{References}

[1] M. P. Velez et al., "Care plans for women pregnant using assisted reproductive technologies: a systematic review," Reprod. Health, Vol. 16(1), PP.9, 2019.

[2] C. De Geyter et al., "ART in Europe, 2014: results generated from European registries by ESHRE: The European IVF-monitoring Consortium (EIM) for the European Society of Human Reproduction and Embryology (ESHRE)," Hum. Reprod., Vol. 33,(9), PP.1586-1601, 2018.

[3] G. Gennarelli et al., "ICSI versus Conventional IVF in Women Aged 40 Years or More and Unexplained Infertility: A Retrospective Evaluation of 685 Cycles with Propensity Score Model," J. Clin. Med., Vol. 8, (10), PP.1694, 2019.

[4] C. Korkmaz, Y. B. Tekin, M. Sakinci, "Effects of maternal ageing on ICSI outcomes and embryo development in relation to oocytes morphological characteristics of birefringent structures," Zygote, Vol. 23,(4), PP.550-555, 2015.

[5] R. M. Smits, R. Mackenzie-Proctor, K. Fleischer, "Antioxidants in fertility: Impact on male and female reproductive outcomes," Fertil. Steril., Vol. 110,(4), PP.578-580, 2018. 
[6] Y. Mouhayar and F. I. Sharara, "Modern management of thin lining," Middle East Fertil. Soc. J., Vol. 22( 1), PP.1-12, 2017.

[7] N. Cicek, O. G. Eryilmaz, E. Sarikaya, , "Vitamin E effect on controlled ovarian stimulation of unexplained infertile women," J. Assist. Reprod. Genet., Vol. 29 (4), PP.325-328, 2012.

[8] M. Akbari-Fakhrabadi et al., "The effect of pentoxifylline and tocopherol combination on endometrium thickness: A systematic review and meta-analysis," J. Food Biochem., Vol. 42(5), p. e12547, 2018.

[9] D. Glujovsky, R. Pesce, G. Fiszbajn, "Endometrial preparation for women undergoing embryo transfer with frozen embryos or embryos derived from donor oocytes," Cochrane database Syst. Rev., Vol. 2(1), PP.12-19, 2010.

[10]N. Ledee-Bataille, F. Olivennes, J. L. Lefaix, "Combined treatment by pentoxifylline and tocopherol for recipient women with a thin endometrium enrolled in an oocyte donation programme," Hum. Reprod., Vol. 17(5), PP.12491253, 2002.

[11]S. Acharya, E. Yasmin, A. H. Balen, "The use of a combination of pentoxifylline and tocopherol in women with a thin endometrium undergoing assisted conception therapies-a report of 20 cases," Hum. Fertil., Vol. 12( 4), PP.198-203, 2009.

[12]H. élène Letur-Konirsch , S. Delanian, "Successful pregnancies after combined pentoxifyllinetocopherol treatment in women with premature ovarian failure who are resistant to hormone replacement therapy," Fertil. Steril., Vol. 79(2), PP.439-441, 2003.

[13]A. Aleyasin, M. Aghahosseini, M. Mohseni, "Effects of pentoxifylline and vitamin $\mathrm{E}$ on pregnancy rate in infertile women treated by ZIFT: a randomized clinical trial,” Int. J. Reprod. Biomed., Vol. 7(4), PP.170-175, 2009.

[14] K. Kitaya, T. Yasuo, Y. Nakamura, "Recovery from endometrial thinning and successful pregnancy following vitamin $\mathrm{E}$ and $\mathrm{C}$ supplementation in infertile woman undergoing myomectomy for diffuse leiomyomatosis of the uterus: a case report," Clin Exp Obs. Gynecol, Vol. 41(3), PP.357-359, 2014.

[15]F. Zal, F. Khademi, R. Taheri, "Antioxidant ameliorating effects against $\mathrm{H} 2 \mathrm{O} 2$-induced cytotoxicity in primary endometrial cells," Toxicol. Mech. Methods, Vol. 28(2), PP.122-129, 2018. 